\title{
Integration of Biomechanical and Biological Characterization in the Development of Porous Poly(caprolactone)-Based Membranes for Abdominal Wall Hernia Treatment
}

\author{
Federico Vozzi $\left(\mathbb{D},{ }^{1}\right.$ Tiziana Nardo, ${ }^{2}$ Ilenia Guerrazzi, ${ }^{1}$ Claudio Domenici, ${ }^{1}$ \\ Silvia Rocchiccioli ${ }^{D},{ }^{3}$ Antonella Cecchettini, ${ }^{3,4}$ Laura Comelli, ${ }^{3}$ Giovanni Vozzi $\left(D,{ }^{5}\right.$ \\ Carmelo De Maria, ${ }^{5}$ Francesca Montemurro, ${ }^{5}$ Gianluca Ciardelli $\mathbb{D}^{2},{ }^{2}$ and Valeria Chiono ${ }^{2}$ \\ ${ }^{1}$ Laboratory of Biomimetic Materials and Tissue Engineering, Institute of Clinical Physiology IFC-CNR, Pisa, Italy \\ ${ }^{2}$ Department of Mechanical and Aerospace Engineering, Polytechnic of Turin, Turin, Italy \\ ${ }^{3}$ Laboratory of Proteomics, Institute of Clinical Physiology IFC-CNR, Pisa, Italy \\ ${ }^{4}$ Department of Clinical and Experimental Medicine, University of Pisa, Pisa, Italy \\ ${ }^{5}$ Research Center "E. Piaggio", University of Pisa, Pisa, Italy \\ Correspondence should be addressed to Federico Vozzi; vozzi@ifc.cnr.it
}

Received 30 July 2018; Revised 10 October 2018; Accepted 24 October 2018; Published 9 December 2018

Academic Editor: Vitor Sencadas

Copyright (C) 2018 Federico Vozzi et al. This is an open access article distributed under the Creative Commons Attribution License, which permits unrestricted use, distribution, and reproduction in any medium, provided the original work is properly cited.

\begin{abstract}
Aims. Synthetic meshes are the long-standing choice for the clinical treatment of abdominal wall hernias: the associated long-term complications have stimulated the development of a new generation of bioresorbable prostheses. In this work, polycaprolactone (PCL) porous membranes prepared by solvent casting/porogen leaching of PCL/poly(ethylene glycol) (PEG) blends with different compositions (different PCL/PEG weight ratios and PEG molecular weights) were investigated to be applied in the field. An optimal porous membrane structure was selected based on the evaluation of physicochemical, biomechanical, and in vitro biological properties, compared to a reference commercially available hernia mesh (CMC). Findings. Selected PCL7-2i membranes, derived from PCL/PEG 70/30 (PCL: $M_{\mathrm{w}}$ 70,000-90,000 Da; PEG: 35,000 Da), showed suitable pore size for the application, intermediate surface hydrophilicity, and biomimetic mechanical properties. In vitro cell tests performed on PCL7-2i membranes showed their cytocompatibility, high cell growth during 21 days, a reduced production of proinflammatory IL-6 with respect to CMC, and a significant secretion of collagen type I. Conclusions. PCL7-2i membranes showed biomimetic biomechanical properties and in vitro biological properties similar to or even better than - in the case of anti-inflammatory behavior and collagen production - CMC, a commercially available product, suggesting potentially improved integration in the host tissue.
\end{abstract}

\section{Introduction}

Ventral hernias are one of most frequent problems associated with major abdominal surgical procedures with an incidence between 2 and $20 \%$ of patients [1], with a recurrence rate of $20-25 \%$ [2]. The high incidence of this side effect generates an important cost for national healthcare systems, with a worldwide estimation of millions of hernia repairs every year (20 millions only for inguinal hernia treatment) [3].

Hernia treatments include a series of options as suture repair and prosthetic materials to reinforce the fascial defect [4]. This last option has shown its potentiality, limiting the recurrence rate with respect to suture repair $[5,6]$, in particular delaying this risk of 2-3 years [7]. Currently, 
implantation of prostheses, able to support damaged tissue in its mechanical and structural functions, represents the care standard treatment. Main advantages of meshes are related to their easy availability and resistance to patients' tissue stresses $[8,9]$.

Synthetic meshes, commonly based on nonresorbable polymers such as polypropylene (PP) and expanded polytetrafluoroethylene (ePTFE), are the long-standing choice in clinical practice since their introduction in the 50s [10]. These materials are effective in hernia treatment with respect to surgical suture but can cause long-term complications such as adhesion formation, graft infection/rejection, fistula formation, and hernia recurrence [11-13]. For all these reasons, research in soft tissue engineering is aimed at realizing a new generation of prostheses able to mimic mechanical properties of host tissue and recreate a physiological environment for its cellular components [14]. One of the possible improvements is development of scaffolds with resorbable properties, in terms of ability to integrate in the host, promotion of new tissue formation, and replacement after a welldefined period. Examples of these materials are VICRYL ${ }^{\mathrm{TM} \circledast}$ (Ethicon Inc., Somerville, NJ, USA) and $\mathrm{DEXON}^{\mathrm{TM} \otimes}$ (Covidien, Mansfield, MA, USA), based on copolymer formulations of poly(glycolic acid) and poly(lactic acid) (PLGA): although able to promote tissue integration, they were rapidly degraded, causing recurrence of hernia due to tissue strength loss [15-17].

Mechanical properties have been improved by Polylactide Mesh $^{\circledR}$ (Ethicon, San Lorenzo, PR, USA), based on polylactide ( $95 \%$ lactide, $5 \%$ glycolide), which however has shown a more severe inflammatory response [14]. TIGR $^{\circledR}$ (Novus Scientific, Uppsala, Sweden), a multifilament mesh based on a fast-degrading PLGA and slow-degrading poly(trimethylene carbonate) (PTMC), and GORE $\mathrm{BIO}-\mathrm{A}^{\circledR}$ (Gore, Newark, DE, USA), an electrospun mesh based on polyglycolic acid (PGA)-PTMC copolymer, have shown limited mechanical load-bearing properties during application [14].

Phasix ${ }^{\circledR}$ (Bard, Warwick, RI, USA), a poly(4-hydroxybutyrate) $(\mathrm{P} 4 \mathrm{HB})$ mesh, has also been introduced having a long degradation time ( $>72$ weeks in male Yucatan swine); however, its long-term in vivo response is unknown [14].

Additionally, bioresorbable polymers, such as polycaprolactone (PCL), polydioxanone (PDO), PLGA, poly(L-lactic acid) (PLLA), and PCL/collagen blends, have been investigated in scientific literature for the preparation of nanofibrous surgical meshes [18]. Although nanofiber texture mimics the extracellular matrix (ECM) structure and facilitates cell attachment, nanofibrous membranes suffer from poor mechanical properties and are unable to support the abdominal wall pressure, especially as soon as the polymer molecular weight decreases during degradation [18].

An alternative scaffold morphology to a typical filament or nanofibrous structure could offer superior mechanical properties allowing the use of bioresorbable polymers in the treatment of abdominal hernia.

PCL, a member of polyesters of the poly $(\alpha$-hydroxyl acid) family, represents a promising candidate for bioresorbable hernia meshes. PCL is a US Food and Drug
Administration-approved polymer, with biocompatible and biodegradable properties, able to favor attachment and growth of different cell types (fibroblasts $[19,20]$, myoblasts [21], chondrocytes [22], and smooth muscle cells [23]) and is commonly used in different biomedical applications [24]. In particular, PCL is widely used for the preparation of scaffolds applied in reparative surgery as treatment of wound healing [25].

In this work, polymeric blends based on PCL with poly (ethylene glycol) (PEG) of two different molecular weights (PEG1: $M_{\mathrm{w}}$ 10,000 Da; PEG2: $M_{\mathrm{w}} 35,000 \mathrm{Da}$ ) were developed for application in hernia treatment and tested for their structural, mechanical, and biological properties compared to a commercial product (CMC, Dipro Medical Devices, San Mauro Torinese, Italy), used as a reference system [26]. The CMC is a nonresorbable composite prosthesis used for ventral hernia repair and made up by a polypropylene lightweight macroporous mesh sewn on a smooth polypropylene film. PEG is a polymer frequently used in tissue engineering thanks to its nontoxicity properties, low protein adhesion, absence of immunogenicity, and solubility in water and organic solvents $[27,28]$. In this work, PEG was used as a porogen blend component. Polymeric blends were analyzed for their physicochemical properties to evaluate morphology, thermal behavior, chemical characteristics, surface wettability, and tensile mechanical properties. In vitro cell tests using human fibroblasts, directly involved in the wound healing process $[29,30]$, were performed to evaluate cell biocompatibility of materials in terms of cytotoxicity and cell growth, inflammatory profile, and modulation of ECM by proteomic analysis.

The integration of biomechanical and biological characterization is fundamental in the development of a new generation of bioengineered scaffolds able to replicate and mimic the host tissue characteristics.

\section{Materials and Methods}

2.1. Materials. PCL $\left(M_{\mathrm{w}}: 70,000-90,000 \mathrm{Da}\right)$ and PEG $\left(M_{\mathrm{w}}\right.$ : 10,000 Da and 35,000 Da, coded as PEG1 and PEG2, respectively) were supplied from Sigma-Aldrich (Milan, Italy), in granular form. All solvents were of analytical grade and used as received (Sigma-Aldrich, St. Louis, MO, USA). CMC was gently furnished by Dipro Medical Devices (San Mauro Torinese, Italy).

2.2. Scaffold Fabrication. Porous PCL membranes were prepared using a solvent casting-leaching method. PCL/PEG1 and PCL/PEG2 100/0, 70/30, 60/40, and 0/100 (wt/wt) blends were prepared using solution mixing. The polymers were dissolved in chloroform at $10 \%(\mathrm{wt} / \mathrm{v})$ concentration. Membranes were obtained by casting a volume of each solution $(10 \mathrm{~mL})$ on glass Petri dishes with $55 \mathrm{~mm}$ diameter. The solvent was removed via evaporation under a fume hood at room temperature for a period of $48 \mathrm{~h}$, and the dried membranes were weighed $\left(W_{0}\right)$. Each membrane was then immersed in deionized water for $48 \mathrm{~h}$ : water was replaced after this time, and membranes were immersed in deionized water for a further $24 \mathrm{~h}$ to assure PEG leaching out. The 
TABle 1: Samples nomenclature before and after the PEG leaching process.

\begin{tabular}{lc}
\hline Before leaching & After leaching \\
\hline PCL & PCL \\
PEG1 & - \\
PEG2 & - \\
PCL/PEG1 70/30 & PCL7-1i \\
PCL/PEG1 60/40 & PCL6-1i \\
PCL/PEG2 70/30 & PCL7-2i \\
PCL/PEG2 60/40 & PCL6-2i \\
\hline
\end{tabular}

obtained porous membranes were dried at $37^{\circ} \mathrm{C}$ for a period of $24 \mathrm{~h}$ and weighed again $\left(W_{\mathrm{f}}\right)$. Samples codes are reported in Table 1. The code for leached samples is "PCL $x-y i$," where $x$ indicates the PCL amount in the initial PCL/PEG blend ( $x=7$ or 6 , indicating that the PCL content in the initial blend was $70 \%$ or $60 \%$, respectively), while $y$ indicates the PEG type used in the blend ( $y=1$ or 2 , indicating PEG1 or PEG 2, respectively).

2.3. PEG Leached Out Percentage. The percentages of PEG leached out from the membranes were calculated according to the

$$
\text { PEG leached out }(\%)=\frac{W_{0}-W_{\mathrm{f}}}{\text { PEG loading weight }} \cdot 100 \text {, }
$$

where $W_{0}$ and $W_{\mathrm{f}}$ are the weights of membranes before and after leaching.

2.4. Scanning Electron Microscopy. Scanning electron microscopy (SEM LEO 1430, Zeiss, Milan, Italy) was performed on the surface and fractured sections (in liquid nitrogen) of membranes before and after PEG leaching. Samples were sputter-coated with gold before SEM analysis. The accelerating voltage was $20 \mathrm{kV}$.

2.5. Differential Scanning Calorimetry. The thermal behavior of membranes, before and after leaching, was investigated by differential scanning calorimetry (DSC) using TA Instruments DSC Q20 (Milan, Italy). Membrane samples $(5-10 \mathrm{mg})$ were weighed in aluminum pans, and nonisothermal scans were performed between $-65^{\circ} \mathrm{C}$ and $100^{\circ} \mathrm{C}$ (first heating; cooling; second heating) at a heating rate of $10^{\circ} \mathrm{C} /$ min under nitrogen atmosphere. The melting temperature $\left(T_{\mathrm{m}} \mathrm{s}\right)$ and enthalpy of fusion $\left(\Delta H_{\mathrm{m}} \mathrm{s}\right)$ of membranes were measured from the second DSC heating scan whereas crystallization temperature $\left(T_{C} s\right)$ and enthalpy $\left(\Delta H_{C} s\right)$ were obtained from the DSC cooling scan. The glass transition temperature $\left(T_{\mathrm{g}} \mathrm{s}\right)$ of PCL, PEG1, and PEG2 was not detected because it was lower than the minimum temperature reachable by the employed DSC apparatus.

Leached membranes were also analyzed by DSC by heating them from room temperature to $120^{\circ} \mathrm{C}$ at $10^{\circ} \mathrm{C} / \mathrm{min}$ to test the efficiency of the drying procedure $(24 \mathrm{~h}$ incubation in an oven at $37^{\circ} \mathrm{C}$ ). The lack of an endothermic peak at $100^{\circ} \mathrm{C}$ due to water evaporation was considered the evidence of effective drying.

2.6. Fourier Transform Infrared Spectroscopy. Chemical analysis of samples before and after leaching has been carried out in a PerkinElmer Frontier Optical Spectrometer fitted with an attenuated total reflection sampler (FTIR-ATR, Milan, Italy). Spectra were recorded over the $400-4000 \mathrm{~cm}^{-1}$ range at room temperature, using diamond crystal, and 32 scans were performed for each sample.

2.7. Contact Angle. The static contact angles of the sample surfaces, before and after leaching, were determined through a sessile drop method, using a $5 \mu \mathrm{L}$ double-distilled water droplet. Static contact angles of membranes were measured in air at room temperature in a CAM $200 \mathrm{KSV}$ instrument (Milan, Italy) equipped with Attension Theta software for data acquisition. The static contact angle value was the average of 15 measures at random areas of each sample membrane.

2.8. Tensile Testing. Mechanical properties of membranes before and after leaching were evaluated by a tensile test on rectangular specimens using the uniaxial tensile testing machine ZwickRoell Z005 (Genoa, Italy). Samples presented a similar size both in the cross-sectional area (thickness $0.35 \pm 0.05 \mathrm{~mm}$, width $9.8 \pm 0.2 \mathrm{~mm}$ ) and in the length $(13.5 \pm 0.2 \mathrm{~mm})$. The tensile force was applied along the length of the samples until fracture, using a preload of $0.05 \mathrm{~N}$ and deformation speed of $0.05 \% / \mathrm{s}$. At least 5 specimens for each type of membrane were tested. The elastic modulus $(E)$, stress at failure, and deformation at failure were measured from the stress-strain curves, derived from the force-displacement curves using a specific sample size. $E$ was evaluated as the slope of the first linear part of the stress-strain curve, and the failure stress and deformation were calculated as the maximum stress a material can withstand and the corresponding deformation, respectively.

$\mathrm{CMC}$ mesh tensile mechanical properties were also analyzed by testing dry rectangular specimens $(50 \times 300 \mathrm{~mm})$ in a $\mathrm{MT}^{\circledR}{ }^{\otimes T e s t}{ }^{\mathrm{TM}} / 10$ instrument (Turin, Italy). The traction force was applied along the length of the samples, at a constant cross-head displacement rate of $100 \mathrm{~mm} / \mathrm{min}$. At least 5 specimens were tested. Failure stress and failure deformation were measured from the stress-strain curves, while $E$ was not evaluated due to the nonhomogeneous structure of samples, characterized by mesh holes.

2.9. Cell Culture. BJ human skin fibroblasts (ATCC-CRL2522, Teddington, UK) were cultured in minimum essential medium (MEM) supplemented with $10 \%$ fetal bovine serum (FBS), $2 \mathrm{mM}$ L-glutamine, $100 \mu \mathrm{U} / \mathrm{mL}$ penicillin, $10-1 \mu \mathrm{U} / \mathrm{mL}$ streptomycin, and $2.5 \times 10-1 \mu \mathrm{U} / \mathrm{mL}$ amphotericin B. All these products were purchased at Sigma-Aldrich (St. Louis, MO, USA). Cells were amplified up to reaching confluence $\left(34000 \mathrm{cells} / \mathrm{cm}^{2}\right)$, and, during this period, the medium was changed every 3 days.

2.10. Cytotoxicity. Cytotoxicity tests were conducted according to the ISO 10993-5 standard. In this study, membranes of 
each material after leaching $\left(18 \mathrm{~cm}^{2}\right.$ surface $)$ were sterilized with $70 \%$ ethanol and ultraviolet (UV) radiation treatment (20 minutes for each side) and then incubated at $37^{\circ} \mathrm{C}$ for $24 \mathrm{~h}$ in $3 \mathrm{~mL}$ of MEM complete medium. The medium was then extracted for further in vitro cell tests (extract medium). The positive control was a complete medium supplemented with $5 \%$ dimethyl sulfoxide (DMSO) $(v / v)$. As negative control, cells cultured in standard medium were used.

Cells were seeded at confluence in a 96-well plate $(\sim 10.000$ cells/well), and, once adhered, $200 \mu \mathrm{L}$ of the medium was exchanged with the extract medium. Cells were placed in an incubator, and, after exposure to the extract medium for $72 \mathrm{~h}$ at $37^{\circ} \mathrm{C}$, changes of cellular morphology were evaluated under an AX70 light-reverted microscope (Olympus, Milan, Italy) and cell viability tests were performed by using Promega CellTiter Blue ${ }^{\circledR}$ (Madison, WI, USA). In each well, $100 \mu \mathrm{L}$ of fresh media was added together with $10 \mu \mathrm{L}$ of reagent. After 150 minutes, the relative fluorescent unit (RFU) values were evaluated with a spectrophotometer plate reader $(579 \mathrm{ex} / 584 \mathrm{em})$. Materials with a viability value of at least $70 \%$ were selected for cell culture growth profile evaluation.

2.11. Cell Culture Growth. Membranes were sterilized with $70 \%$ ethanol and UV radiation treatment (20 minutes for each side) and left in contact with the medium for 2 hours before cell seeding. Cells at confluence were washed with phosphate-buffered saline (PBS), detached by trypsin $(0.25 \%(w / v))$, and placed in contact with a fresh complete medium to deactivate enzyme action. Fibroblasts were counted with a hemocytometer and seeded on materials, placed in a 6-well plate at a cell density of $15 \%$ (equivalent to $\sim 50.000$ cells/well). At well-defined time $(3,7,14$, and 21 days) cell viability test was performed with CellTiter Blue ${ }^{\circledR}$.

In order to count cells, a standard curve of fibroblasts on culture plates was obtained. Cells were seeded in 24-well plates at several concentrations (from 5000 to 70,000 cells/ well), in duplicate. Once adhered, $50 \mu \mathrm{L}$ of CellTiter Blue ${ }^{\circledR}$ was added to each well and, after 150 minutes, RFU emitted by dye was evaluated as above.

At the 21 st day, samples were fixed with $4 \%$ paraformaldehyde solution for 30 minutes at room temperature and preserved in $\mathrm{PBS}$ at $4^{\circ} \mathrm{C}$ for immunohistochemistry protocol.

2.12. Cytokine Production. The medium at 7,14 , and 21 days was collected and stored at $-80^{\circ} \mathrm{C}$ until cytokine analysis. IL-6 quantification was performed by use of Elecsys IL-6 assay (Roche Diagnostics, Milan, Italy), an electrochemioluminescent immunoassay (ECLIA).

Analysis of IL-10 was performed using ELISA kit assay (Boster Biological Technology, Fremont, CA, USA).

2.13. Immunohistochemistry. Paraformaldehyde-fixed samples were treated for evaluation of collagen type I and type III production. Collagen type I was recognized by anti-human COL1A1 goat primary antibody and relative FITC-conjugated secondary antibody (donkey anti-goat IgG-FITC); collagen type III was identified by anti-human COL3A1 goat primary antibody and relative rhodamine- conjugated secondary antibody (bovine anti-rabbit IgG-R). All the antibodies were purchased at Santa Cruz Biotechnology (Dallas, TX, USA). Samples were washed three times with PBS and treated with $0.1 \%$ Triton in PBS for 2 minutes at room temperature to permeabilize cell membranes. Samples were left in 5\% BSA for 30 minutes and then treated with a mix of the two primary antibodies, $1: 100$ diluted in $1 \% \mathrm{BSA}$, for 1 hour at $37^{\circ} \mathrm{C}$. Then, a mix of the secondary antibodies 1:200 diluted in 1\% BSA was added to the samples for 1 hour at $37^{\circ} \mathrm{C}$. Fifteen minutes before the end of incubation, DAPI (4',6-diamidino-2-phenylindole) was added to each sample at $1: 1000$ dilution to detect cell nuclei. Finally, samples were analyzed by means of a fluorescence microscope (CX40, Olympus, Milan, Italy).

2.14. ECM Extraction. Cells were seeded on PCL7-2i membranes and CMC mesh and cultured for 7 days. Cells were removed and ECM recovered as described in [26].

2.15. Sample Processing and Liquid ChromatographyTandem Mass Spectrometry with SWATH ${ }^{T M}$-Based Analysis (LC-MS/MS SWATH) for Proteomics. For sample treatment and LC-MS/MS analysis, the same protocol described in Vozzi et al. [26] was used. Briefly, protein concentration was determined by bicinchoninic acid assay (Pierce, Thermo Scientific, Waltham, MA, USA). About $40 \mathrm{mg}$ of protein was dissolved in ammonium bicarbonate $25 \mathrm{mM}$, reduced with dithiothreitol $5 \mathrm{mM}$ at $80^{\circ} \mathrm{C}$ for $30 \mathrm{~min}$, and alkylated using iodoacetamide $10 \mathrm{mM}$ at $37^{\circ} \mathrm{C}$ for $20 \mathrm{~min}$. Digestion was obtained incubating overnight with 1:100 Trypsin (Roche, Basel, Switzerland): substrate at $37^{\circ} \mathrm{C}$. Peptide mixtures were acidified and then loaded on a C18 cartridge in order to eliminate debris and additionally purified with $0.22 \mu \mathrm{m}$ filters. Peptides were diluted to $0.1 \mu \mathrm{g} / \mu \mathrm{L}$ by $2 \%$ acetonitrile (ACN, Romil, UK) $/ 0.1 \%$ formic acid (FA); $5 \mu \mathrm{L}$ was injected for library searching and $2 \mu \mathrm{L}$ in duplicate for SWATH ${ }^{\mathrm{TM}}$ method analysis.

Chromatographic separation of peptides was performed using a nano-HPLC system (Eksigent, AB Sciex, Washington, DC, USA). Peptides eluted from chromatography were directly processed using a 5600 TripleTOF $^{\mathrm{TM}}$ mass spectrometer (AB Sciex) equipped with a DuoSpray ${ }^{\mathrm{TM}}$ ion source $(\mathrm{AB}$ Sciex). Data were acquired using the SWATH ${ }^{\mathrm{TM}}$ method for shotgun data-independent MRM quantification. For library, MS/MS data were processed with ProteinPilot ${ }^{\mathrm{TM}}$ Software (AB Sciex). The false discovery rate (FDR) analysis was set to a confidence level of $95 \%$.

2.16. Statistical Analysis. All data were expressed as mean \pm standard deviation obtained by at least five different experiments. Differences between groups were evaluated by oneway ANOVA and Student $t$-test; Prism 7 software was used for statistical analysis. Values were considered statistically significant for $p$ value $<0.05$. For proteomics data, to evaluate differentially expressed proteins between CMC and PCL7-2i at 7 days, MarkerView 1.2 software was used. Three technical replicates for biological sample were used. The two groups were compared by $t$-test statistics: paired $t$-test was used as a statistical parameter between the means of continuous 
TABle 2: Percentage of weight loss in blends due to PEG dissolution and percentage of undissolved PEG with respect to the initial PEG amount.

\begin{tabular}{ccc}
\hline Samples & Weight loss after leaching (\%) & Undissolved PEG (\%) \\
\hline PCL7-1i & $29.4 \pm 0.6$ & $2.0 \pm 0.2$ \\
PCL7-2i & $28.8 \pm 0.6$ & $4.0 \pm 0.2$ \\
PCL6-1i & $38.9 \pm 0.3$ & $2.8 \pm 0.8$ \\
PCL6-2i & $38.8 \pm 0.0$ & $3.0 \pm 0.0$ \\
\hline
\end{tabular}

variables to determine significant differences between the two categories of mass spectrometric data. A $p$ value $<0.05$ and a fold change $>2$ were considered significant to validate differences between categories.

\section{Results}

3.1. PEG Leached Out Percentage. Incubation of PCL/PEG1 and PCL/PEG2 blend films in a water bath almost caused an approximately complete dissolution of the PEG component leaving porous membranes (Table 2). The percentage of leached out PEG corresponds to the porosity degree of membranes. A small percentage of PEG with respect to the initial amount was still present in blends (Table 2).

3.2. Morphological Characterization by Scanning Electron Microscopy (SEM). Figure 1 shows the SEM images of the external surface and fractured section of PCL/PEG1 and PCL/PEG2 blends.

Blend films showed a compact section. No evident phase separation between blend components was observed in any of the blend compositions.

Morphological evaluation was also conducted on PCLbased membranes after PEG dissolution (Figure 1). Surfaces were scarcely porous. On the contrary, fractured sections were highly porous with homogeneous distribution of pores with spherical shape.

3.3. Thermal Properties by Differential Scanning Calorimetry (DSC). The first heating scan of leached samples confirmed the complete lack of water as the endothermic peak associated with water evaporation was not present (data not shown). Hence, the efficiency of the employed drying protocol (sample incubation for $24 \mathrm{~h}$ at $37^{\circ} \mathrm{C}$ ) was demonstrated.

Figure 2 collects DSC second heating thermograms for PCL, PCL/PEG1, and PCL/PEG2 film samples before and after PEG removal. The analysis of the second heating scan allows a comparison of material properties after deleting the thermal history.

PEGs and PCL are semicrystalline polymers characterized by a melting temperature $\left(T_{\mathrm{m}}\right)$. PEG and PCL glass transition temperatures could not be detected by DSC analysis, as they are both at $-67^{\circ} \mathrm{C}[31]$, corresponding to the limit cooling temperature of the DSC instrument used in this work. For each blend, a double melting peak (Table 3) was detected, due to the different melting temperatures of the blend components. In blends, $T_{\mathrm{m}}$ of PCL phase did not vary, while a slight decrease was observed for the melting peaks of
PEG1 and PEG2 phases with respect to pure PEGs (Figure 2, $\mathrm{B} 1$ and $\mathrm{B} 2$ ).

The cooling scans of PCL, PEG1, and PEG2 samples showed a crystallization event (Figure 2, A1 and A2). On the contrary, PCL/PEG1 blend films were characterized by three $T_{\mathrm{c}}$ (Table 3): the lower $T_{\mathrm{c}}$ was related to the crystallization by homogeneous nucleation of PEG1 $\left(1.6 \pm 0.1^{\circ} \mathrm{C}\right.$ for PCL/PEG1 $70 / 30$ and $2.4 \pm 0.2^{\circ} \mathrm{C}$ for PCL/PEG1 60/40), the intermediate $T_{\mathrm{c}}$ was due to PCL crystallization (at around $23^{\circ} \mathrm{C}$ ), and the higher $T_{c}$ was associated to PEG1 heterogeneous nucleation $\left(35.5 \pm 0.4^{\circ} \mathrm{C}\right.$ for PCL/PEG1 $70 / 30$ and $39.1 \pm 1.4^{\circ} \mathrm{C}$ for PCL/PEG1 60/40) [32]. In blends, $T_{c}$ values of PEG1 and PCL (considering for PEG1 the heterogeneous crystallization only) decreased compared to the pure polymers. The presence of the homogeneous PEG1 nucleation mechanisms was ascribed to a fine dispersion of PEG1 in the PCL matrix.

For blends containing PEG2, the crystallization of PEG2 through two different nucleation mechanisms, homogeneous and heterogeneous, was observed only for PCL/PEG2 60/40 blend films, respectively, at $1.4 \pm 0.4^{\circ} \mathrm{C}$ and $40.0 \pm 0.7^{\circ} \mathrm{C}$. Similarly to that observed for PCL/PEG1 blends, $T_{c}$ values of PCL and PEG2 (considering crystallization by heterogeneous nucleation mechanism for PEG2 in PCL/PEG2 60/40 blends) slightly decreased with respect to pure polymers.

On the other hand, the PCL/PEG2 70/30 blend only showed PEG2 crystallization by homogeneous nucleation. Hence, PCL/PEG2 70/30 blend samples only showed two distinct $T_{c}$ at about $1.5^{\circ} \mathrm{C}$ (crystallization of PEG2 by homogeneous nucleation) and $25^{\circ} \mathrm{C}$ (crystallization of PCL). The presence of a unique crystallization temperature for PEG2 phase could be due to a finer dispersion of PEG2 in the PCL matrix (Table 3).

After PEG removal, all the membranes showed only a characteristic thermal event, both in the cooling scan and in the second heating scan, attributed to PCL crystallization and melting, respectively. In porous membranes, the cooling and melting enthalpies of PCL were slightly higher compared to the values of control PCL samples, suggesting a slightly higher crystallization degree of porous membranes.

After PEG dissolution (Table 3), the characteristic thermal transitions associated with PEG phase could not be detected. This could be due to a complete removal of PEG or to the permanence of a very small amount of PEG which thermal transitions cannot be detected by DSC analysis.

3.4. Chemical Analysis by FTIR-ATR. Characteristic FTIRATR absorption bands (Supplementary Material Figure S1) of PCL and PEG could be detected in the FTIR-ATR spectra of blend films. In particular, a sharp band at around $1726 \mathrm{~cm}^{-1}$ was observed, corresponding to the carbonylstretching of PCL. When the content of PEG increased, no appreciable shift of this band was observed suggesting poor interaction between the phases.

After PEG removal, absorption bands attributed to the PEG2 component were no more detected in the FTIR-ATR spectra of porous films, such as the asymmetric stretching vibrations of C-O-C bonds at around $1280 \mathrm{~cm}^{-1}$. This result 


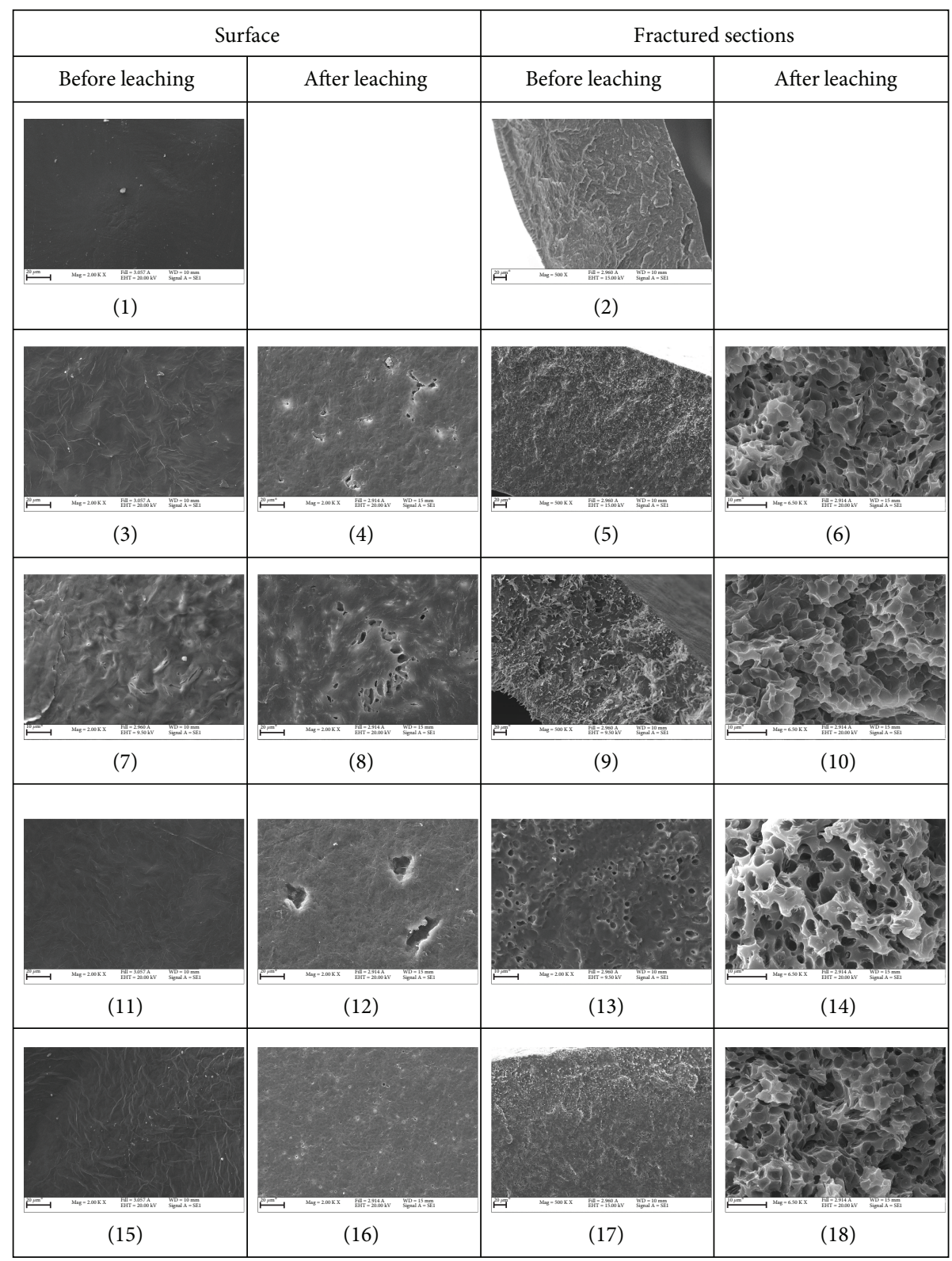

FIGURE 1: SEM images of the surface and fractured sections of materials before (odd numbers) and after (even numbers) leaching: PCL (1, 2), PCL/PEG1 70/30 (3, 5), PCL7-1i (4, 6), PCL/PEG1 60/40 (7, 9), PCL6-1i (8, 10), PCL/PEG2 70/30 (11, 13), PCL7-2i (12, 14), PCL/PEG2 60/40 $(15,17)$, and PCL6-2i $(16,18)$. Scale bar $=20 \mu \mathrm{m}$ for surfaces and $10 \mu \mathrm{m}$ for section images.

confirmed the complete removal of porogen from PCL/PEG blend films (Supplementary Material Figure S1).

3.5. Surface Wettability Properties. Table 4 collects the static contact angle for all samples, before and after leaching. PCL samples $\left(73.1 \pm 2.8^{\circ}\right)$ were markedly less hydrophilic than PEG1 $\left(41.5 \pm 2.9^{\circ}\right)$ and PEG2 $\left(44.0 \pm 1.9^{\circ}\right)$ samples (for both comparison, $p<0.05)$. The surface static contact angle of PCL/PEG1 cast films decreased as the amount of PEG1 increased: it was $71.5 \pm 2.4^{\circ}$ for blends containing $30 \%$ wt. PEG1 and $44.7 \pm 2.6^{\circ}$ for blend containing $40 \%$ wt. PEG1. On the contrary, the static contact angle of PCL/PEG2 blend samples did not change significantly with increasing PEG2 content $\left(49.1 \pm 3.0^{\circ}\right.$ for PCL/PEG2 $70 / 30$ and $51.2 \pm 2.5^{\circ}$ for PCL/PEG2 60/40), although it was lower than for PCL.

After leaching, surface wettability decreased for all the samples. Porous films with PEG1 as porogen showed the highest contact angle values $\left(110.0 \pm 6.8^{\circ}\right.$ for PCL7-1i and $82.9 \pm 7.4^{\circ}$ for PCL6-1i) while PCL7-2i and PCL6-2i retained surface hydrophilicity with contact angles of $67.8 \pm 3.9^{\circ}$ and $66.8 \pm 6.1^{\circ}$

3.6. Mechanical Characterization. The mechanical properties of the tested materials including the elastic modulus, the maximum load, and the deformation at maximum load are reported in Figure 3. 


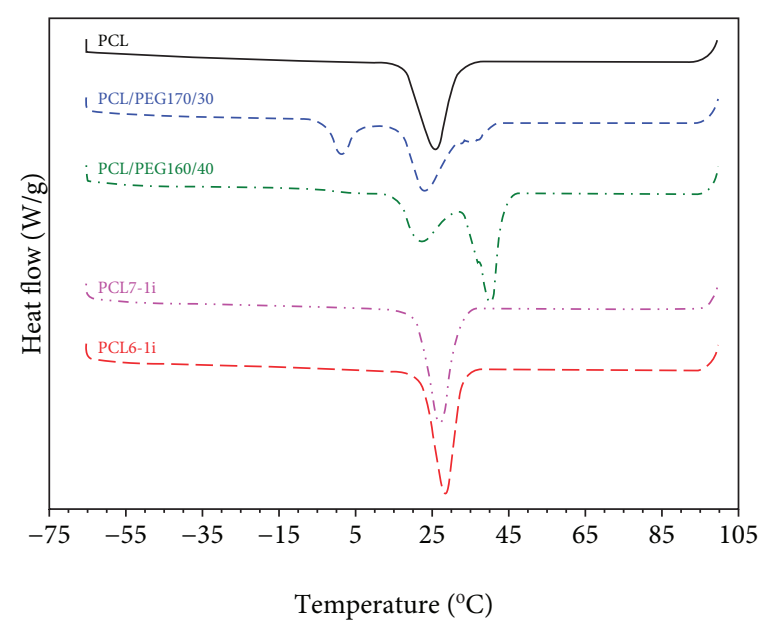

(a1)

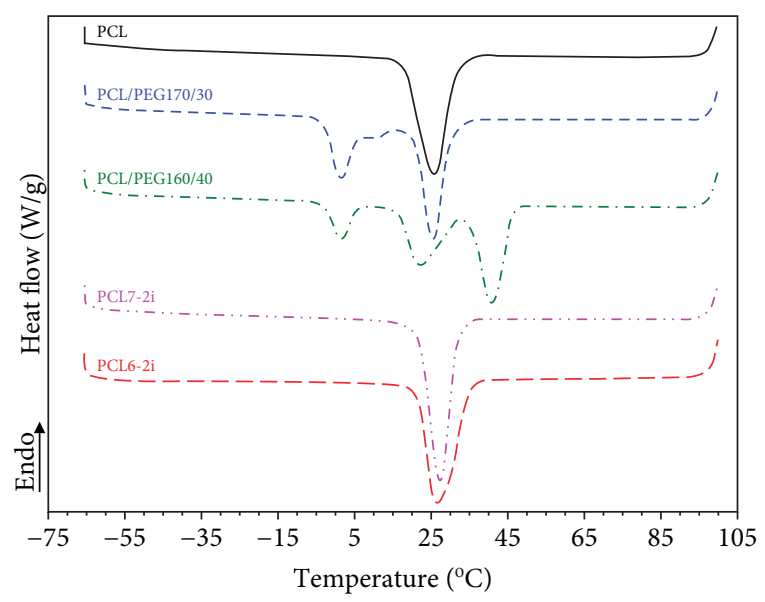

(a2)

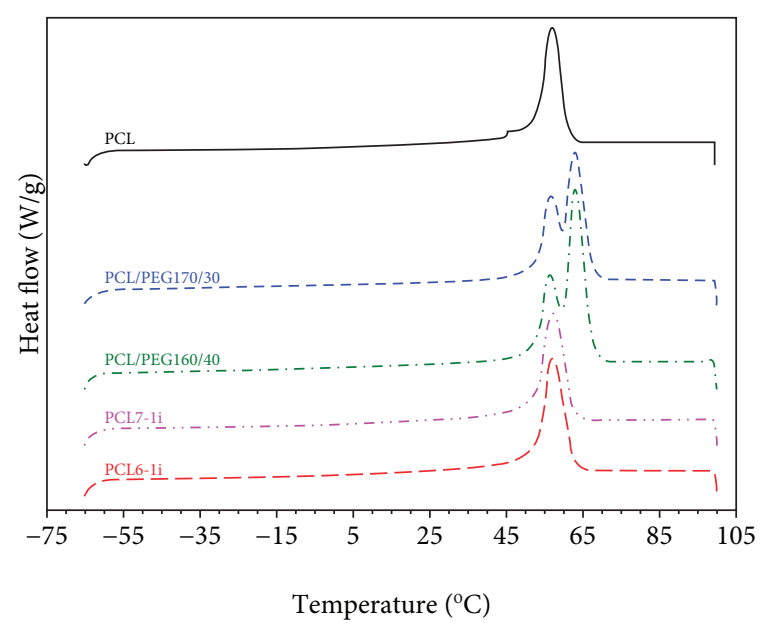

(b1)

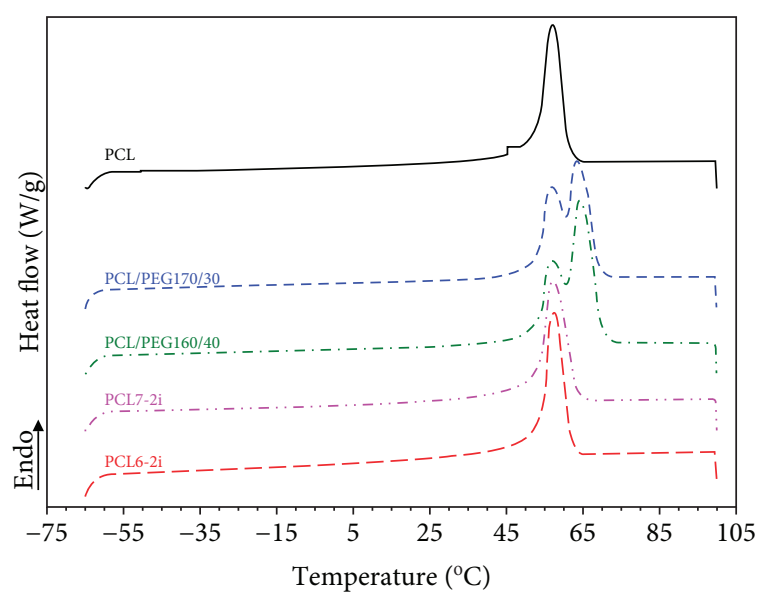

(b2)

FIGURE 2: Comparison of DSC cooling thermograms (a1 and a2) and second heating thermograms (b1 and b2) for PCL/PEG1 (numbers 1) and PCL/PEG2 (numbers 2) samples, before and after leaching.

The elastic modulus increased with increasing PCL content (Figure 3(a)). The elastic modulus of PCL/PEG2 blends was higher than that of PCL/PEG1 blends with the same composition. The same trend is confirmed after the leaching process: PEG2-derived samples have a higher elastic modulus than the corresponding PEG1-derived ones. In both cases, the leaching process leads to less rigid structures with respect to nonleached samples.

Similarly, failure stress increased with increasing content of PCL (Figure 3(b)), with higher values for PCL/PEG2 blends, for both leached and nonleached samples. The leaching process decreases the failure stress. The stress at failure of $\mathrm{CMC}$ was $2.4 \pm 0.3 \mathrm{MPa}$.

Before leaching, the deformation at failure (Figure 3(c)) was similar for all blend samples and significantly lower than that of pure PCL. After leaching, samples showed higher deformability: particularly, PCL/PEG2-based blends had higher failure deformation. CMC deformation at failure was $49.1 \pm 3.5 \%$, significantly higher than for PCL samples.

3.7. In Vitro Cytotoxicity. Cytotoxicity tests showed that all the porous and nonporous materials presented after 3 days the same viability (>95\%) with respect to negative control (untreated cells, 100\%) and to CMC (>95\%), with values above the threshold of 70\% indicated by ISO 10993-5 (data not shown).

3.8. In Vitro Cell Growth Tests. The tests were only performed on porous samples, as for the PCL/PEG blends: PEG would be released in the culture medium during the test, and their elastic modulus was too high with respect to reference meshes for hernia prostheses [33]. Results showed that only PCL7-2i presented a good cell growth trend, with a continuous increase in cell viability (Figure 4) superimposable to control and CMC.

3.9. Inflammatory Profile. Based on the results of cytocompatibility and cell growth tests, PCL7-2i membranes were selected to perform the analysis on inflammatory profile by anti- (IL-10) and pro- (IL-6) inflammatory markers. As shown in Figure 5, the initial anti-inflammatory profile of PCL7-2i (Figure 5(a)) was substituted by a proinflammatory trend (Figure 5(b)), with IL-6 final concentration 4 times 


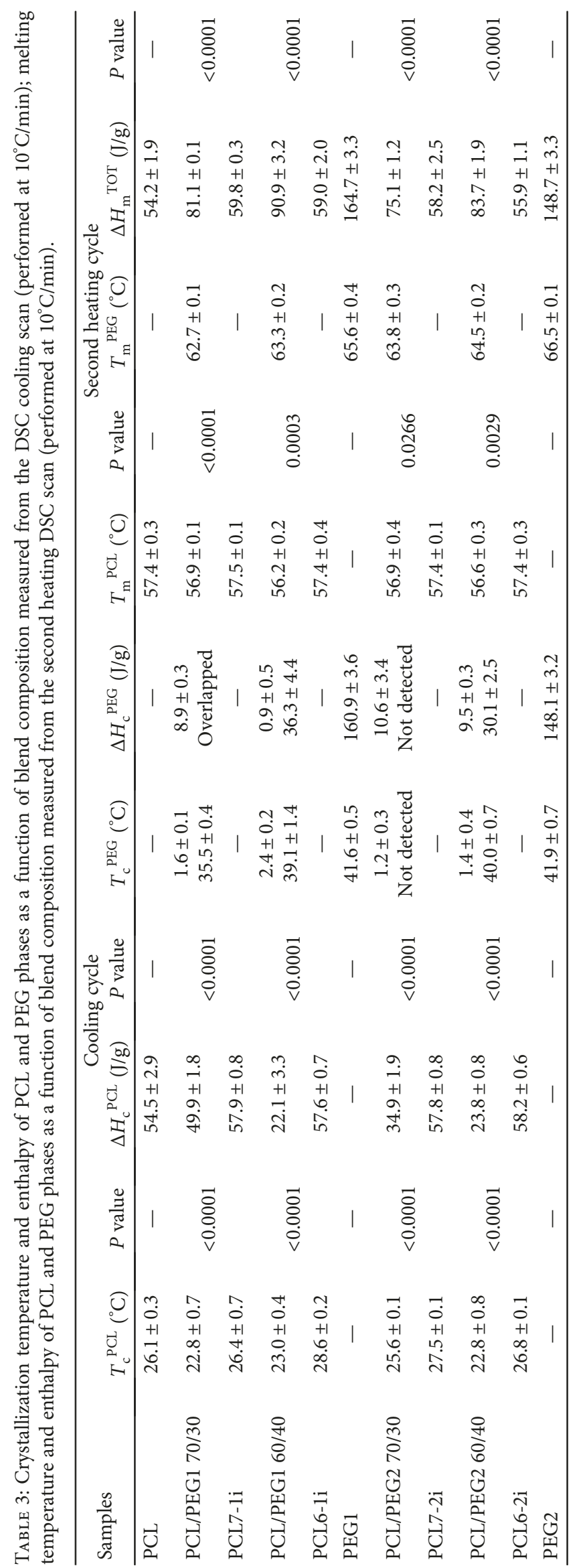


TABLE 4: Static contact angle values of samples before and after leaching.

\begin{tabular}{lcccc}
\hline Before leaching & $\begin{array}{r}\text { Contact } \\
\text { angle }\left(^{\circ}\right)\end{array}$ & $\begin{array}{c}\text { After } \\
\text { leaching }\end{array}$ & $\begin{array}{c}\text { Contact } \\
\text { angle }\left(^{\circ}\right)\end{array}$ & $P$ value \\
\hline PCL & $73.1 \pm 2.8$ & - & - & - \\
PEG1 & $41.5 \pm 2.9$ & - & - & - \\
PEG2 & $44.0 \pm 1.9$ & - & - & - \\
PCL/PEG1 70/30 & $71.5 \pm 2.4$ & PCL7-1i & $110.0 \pm 6.8$ & $<0.0001$ \\
PCL/PEG1 60/40 & $44.7 \pm 2.6$ & PCL6-1i & $82.9 \pm 7.4$ & $<0.0001$ \\
PCL/PEG2 70/30 & $49.1 \pm 3.0$ & PCL7-2i & $67.8 \pm 3.9$ & $<0.0001$ \\
PCL/PEG2 60/40 & $51.2 \pm 2.5$ & PCL6-2i & $66.8 \pm 6.1$ & 0.0007 \\
\hline
\end{tabular}

higher with respect to day 7 , but with reduced levels with respect to CMC.

3.10. Immunohistochemistry. Finally, also type I and type III collagen production was semiquantitatively evaluated with immunohistochemistry and the type I collagen/type III collagen ratio quantified. In control conditions, BJ fibroblast cells produced type III collagen (neo-formed type) and, in small quantity, type I (stable) collagen (Figure 6(a)). PCL7-2i reduced the production of type III collagen favoring a strong and significant increase $( \pm 3$ times, $p<0.0001)$ of type I collagen. This trend was also confirmed by the type I collagen/ type III collagen ratio (Figure 6(b)), which showed a value near $0.8(p<0.0001)$.

3.11. ECM Protein Characterization. ECM proteins were extracted from CMC and PCL7-2i membranes and analyzed by mass spectrometry that allowed the identification of 243 proteins (Supplementary Material Table S1). Proteins were classified according to their localization (Supplementary Material Figure S2), and up to 125 were ECM, ECMassociated, or membrane proteins. Of these, four resulted to be differentially expressed when samples from CMC and PCL7-2i were compared (Table 5).

\section{Discussion}

This work was aimed at the preparation and characterization of porous PCL membranes to be used as a new generation of resorbable hernia meshes. Particularly, porous PCL membranes were characterized for their physicochemical, mechanical, and biological characteristics, comparing results with the performance of a commercially available CMC mesh: this lightweight polypropylene mesh is able to favor cell colonization, generating a series of biochemical modifications in terms of typical inflammatory reaction, collagen production, and ECM expression [26]. However, the lightweight mesh is not suitable to prevent adhesion to internal organs [34]. On the contrary, the polypropylene film does not induce the formation of adhesion to viscera due to its plane surface and its antiadhesive features shown in Wistar rats [33] and in clinical studies [35, 36].

In our work, porous membranes with an asymmetric structure characterized by a poorly porous skin layer and high internal porosity were obtained. As the amount of dissolved PEG was approximately equal to the amount of incorporated PEG, the porosity degree was $29.4 \pm 0.7 \%$ and $28.8 \pm 0.6 \%$ for PCL7-1i and PCL7-2i samples and $38.9 \pm$ $0.3 \%$ and $38.8 \pm 0.0 \%$ for PCL6-1i and PCL6-2i, respectively. PCL and PEG have a different polarity (PCL is poorly hydrophilic while PEG is highly hydrophilic as suggested by contact angle measurements) and consequent weak reciprocal interactions: for this reason, the PEG phase formed spherical dispersed domains in the PCL matrix, leading to spherical pores of approximately $5 \mu \mathrm{m}$ size after PEG removal. Additionally, the pore surface was smooth. These results suggested that PEG and PCL were immiscible, which was in agreement with previous findings in the scientific literature [37]. Indeed, FTIR-ATR analysis showed that the carbonyl stretching band of PCL did not shift as a function of blend composition, confirming poor interaction between blend components. This result suggested that any interaction between PCL and PEG2 was weak, and this conclusion was consistent with DSC data. However, this result was opposite to the findings by Ozeki et al. [38] who found interactions between PEG and a carboxyvinyl polymer, having the same carboxyl functional group of PCL. Probably, the different polarities between PEG and PCL (PEG is highly hydrophilic while PCL is poorly hydrophilic as suggested by static contact angle measurements) hindered the formation of a sufficiently high number of hydrogen bonding to detect shifts of the PCL carbonyl FTIR-ATR band.

Thermal characterization by DSC analysis showed that the presence of partially crystallized PEG phase in blends decreased the PCL phase crystallization rate, causing a slight decrease in PCL $T_{c}$. This result was not observed for PCL/ PEG2 70/30 blends where PEG2 was still in a molten state during PCL crystallization, while it underwent crystallization at lower temperature than PCL by a homogeneous nucleation mechanism. On the other hand, the PCL crystallization degree slightly increased in porous membranes with respect to compact PCL films, suggesting some nucleating effect of PEG component. However, the $T_{\mathrm{m}}$ of the PCL phase remained unchanged in blends before and after PEG removal, suggesting that the perfection degree of PCL crystals was similar in all the samples.

Importantly, DSC analysis suggested a different interaction between blend components, depending on the molecular weight of PEG: a higher amount of PEG tended to crystallize by a homogeneous crystallization mechanism in PCL/PEG2 blends vs. PCL/PEG1 blends with the same composition, as suggested by the corresponding crystallization enthalpy values. The homogeneous crystallization behavior of PEG2 in PCL/PEG2 blends was indicative of a distribution of PEG2 in domains with smaller size compared to the PEG1 ones in PCL/PEG1 blends. This difference was attributed to the higher molecular weight of PEG2 with respect to PEG1: during solvent evaporation for membrane formation, coalescence phenomena of PEG2 phase were partially hindered by its higher molecular weight. Hence, PEG2 domains retained a smaller size compared to PEG1 domains in PCL/PEG1 blends.

Porous films obtained using PEG1 as porogen showed surface hydrophobicity (static contact angle of $110.0 \pm 6.8^{\circ}$ 


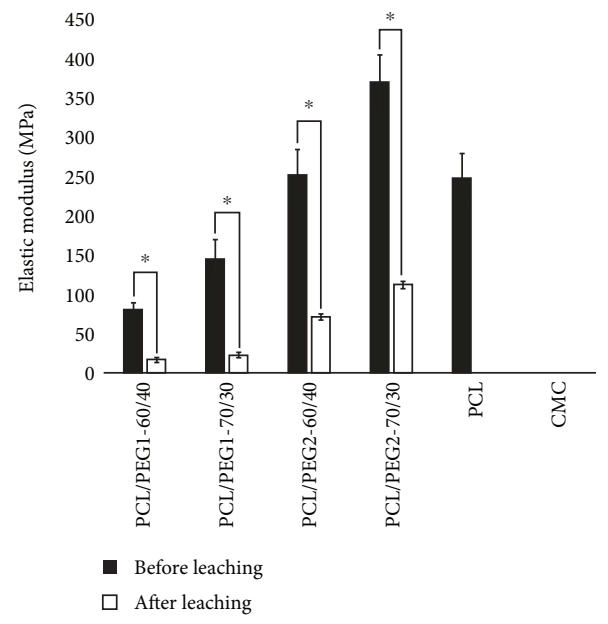

(a)

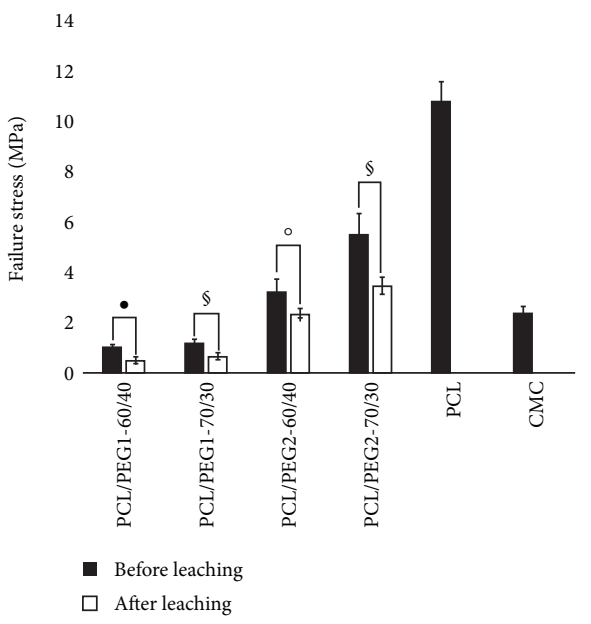

(b)

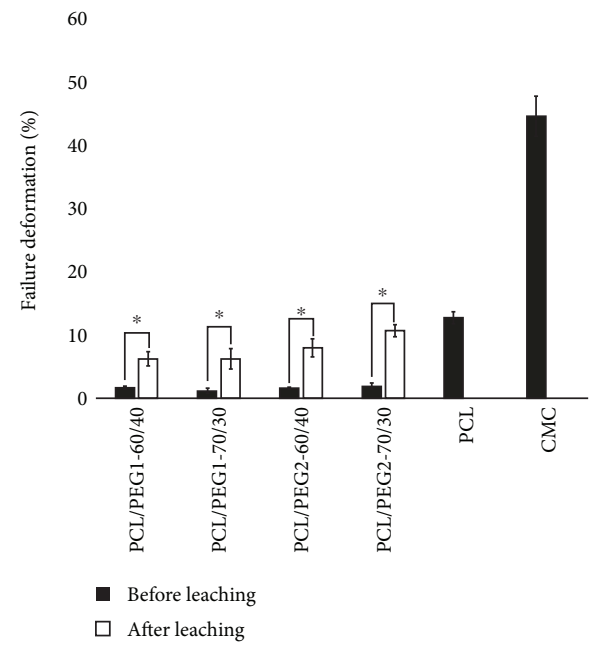

(c)

FIgURe 3: Comparative analysis of elastic modulus (a), failure stress (b), and failure deformation (c) for PCL/PEG blends before and after leaching. ${ }^{*} p<0.0001,{ }^{\bullet} p=0.0002,{ }^{\S} p=0.0008$, and ${ }^{\circ} p=0.0086$.

for PCL7-1i) or poor hydrophilicity (static contact angle of $82.9 \pm 7.4^{\circ}$ for PCL6-1i). On the other hand, PCL7-2i and PCL6-2i were more hydrophilic with contact angles of $67.8 \pm$ $3.9^{\circ}$ and $66.8 \pm 6.1^{\circ}$, respectively. The different types of dispersion for PEG1 and PEG2 in PCL/PEG blends were probably the cause for a different organization of PCL chains on the surface: in the case of porous samples from PCL/ PEG2 blends, hydrophilic carboxylic moieties were probably preferentially distributed on the sample surface. Additionally, differences in surface morphology also affected surface wettability.

Mechanical analysis was performed on PCL/PEG membranes and porous PCL films (Figure 3), in order to characterize and select biomechanical features similar to meshes for hernia repair currently used in clinics. Meshes should be strong enough to resist the state of stress present in the adnominal wall and at the same time not so stiff to cause discomfort and pain to patients. Literature reference values for the elastic modulus of hernia meshes are 20-120 MPa [33].
The elastic modulus increased with increasing PCL content, both before and after the leaching process. The molecular weight of PEG had influence on mechanical properties: the elastic modulus of PEG2-derived blends (PEG2: 35000 Da) was higher than that of PEG1-derived ones (PEG1: $10000 \mathrm{Da}$ ).

Interestingly, the elastic modulus of the PCL/PEG2 70/30 blend was higher with respect to that of PCL, while the elastic modulus of the PCL/PEG1 70/30 blend was significantly lower with respect to that of PCL. This behavior was probably due to the different interaction degrees between blend components and the different blend morphologies when using PEGs with different molecular weights. Indeed, DSC analysis suggested that the PEG2 component was finely distributed in the PCL/PEG2 70/30 blend; this was probably the reason for its superior mechanical performance respect to the PCL/ PEG1 70/30 blend. After the leaching process, the elastic modulus of porous samples obtained from PCL/PEG2 blends was higher than for samples prepared from PCL/PEG1 blends, again suggesting a finer and more homogeneous pore 


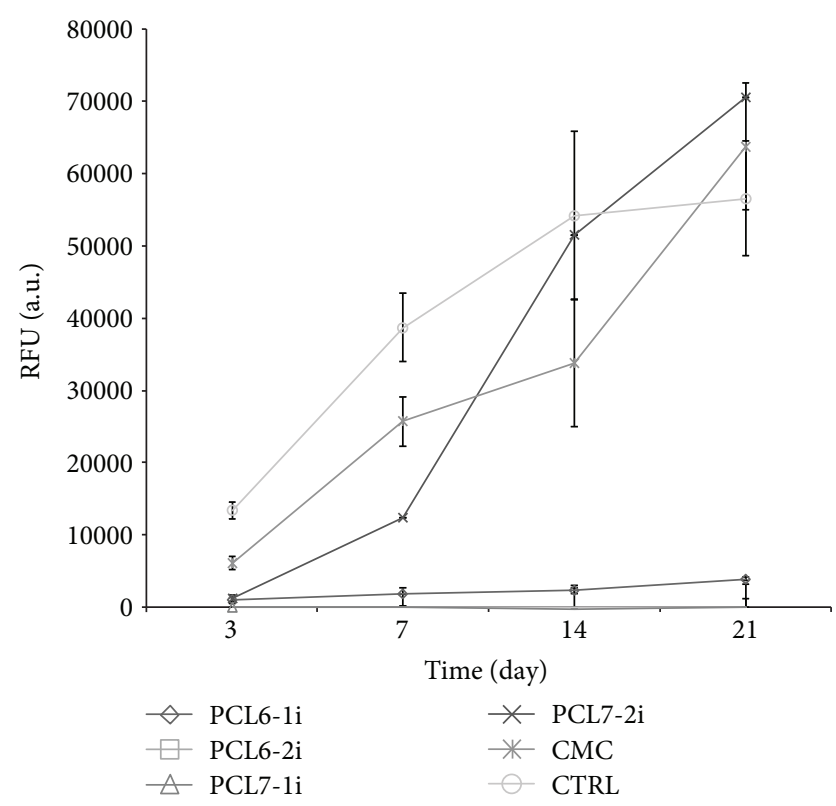

Figure 4: Cell growth curve (time = 21 days).

morphology. In both cases, after leaching, the resulting porous structures present an elastic modulus significantly lower than that of the corresponding nonleached samples.

Similarly, the failure stress increased with increasing PCL content (Figure 3(b)) due to the superior mechanical performance of PCL with respect to PEG in nonleached blends and due to the lower porosity in the case of leached samples. As for the elastic modulus, the failure stress of PCL/ PEG2 was higher with respect to PCL/PEG1 blends, both before and after leaching. This behavior, again, can be addressed to a different pore morphology, depending on the molecular weight of PEG. The leaching process increases the deformation at failure (Figure 3(c)), which presented marked lower values in nonleached samples with respect to pure PCL samples, again suggesting a more homogeneous and finer pore structure.

As a conclusion, higher concentrations of PEG resulted into more porous and less stiff membranes, but interestingly PEG with the highest molecular weight (PEG2) resulted to be more finely dispersed and led to stiffer structures. After leaching, the membranes showed an elastic modulus in the same range of meshes for hernia prosthesis and thus suitable for applications in hernia repair. This is the first time that the solvent-casting/porogen leaching technique of PCL/PEG blends is exploited for the preparation of scaffolds with suitable properties for the treatment of abdominal wall hernia and as an alternative to electrospun scaffolds or filamentbased meshes [14].

For biological characterization, BJ human skin fibroblasts were selected for tests on materials under investigation, according to their role in the wound healing process. In fact, they represent a cell barrier respect to prosthesis, regulate reparative process by secretion of growth factors, and modulate the surrounding cell environment [39].

All the samples showed an optimal cell biocompatibility compared to the negative control. Cell growth analysis, performed on porous samples, allowed a further selection of materials under investigation. In fact, PCL6-1i, PCL6-2i, and PCL7-1i showed nonadhesive and nonproliferative cell properties, while PCL7-2i was characterized by progressively increasing cell colonization on its surface. Hydrophobicity together with mechanical and structural properties of PCL7-2i seems to produce a positive effect on its capabilities to support cell colonization.

Based on these results, PCL7-2i membranes were selected for further analyses. The inflammatory profile showed an initial increase of the anti-inflammatory IL-10 cytokine [40] followed by a strong increase of the proinflammatory one, IL-6 [41], with reduced the magnitude with respect to CMC. This trend was highlighted in our previous work [26] and in literature [42]: inflammation is a typical body response to surgery implant and can support mesh colonization and integration [43]. This type of response probably could be related to their surface and mechanical properties, which, interacting with cells, modulate their chemomechanical signal integration and stiffness sensing and stimulate the secretion of inflammatory mediators $[44,45]$.

The biological characterization of PCL7-2i foresaw the immunohistochemical analysis of two of the main components of ECM produced by fibroblasts: collagen I and collagen III. PCL7-2i stimulated the production, at 21 days, of mature collagen type I with respect to type III in comparison to control and CMC mesh, confirmed also by the collagen type I/III ratio (value near 0.8 ). These two proteins are heavily involved in mesh integration during prosthesis implant where a remodeling process produces an initial increase in the secretion of immature type III, followed by production of mature type I [46-48]. Literature showed how a decreased ratio could be of significant importance in the hernia pathophysiology probably leading to structural and mechanical stability alteration of mesh in the host tissue [49]. The increased production of collagen type I observed in our experimentation and results of the inflammatory profile suggest a potential stable in vivo mesh implant favoring tissue integration of and a contemporary reduction of host rejection processes.

Interestingly, proteomics analyses were validated and, at the same time, confirmed the histological data: among the differentially expressed proteins (Table 5), collagen type III resulted to be significantly overexpressed at day 7 in ECM from PCL7-2i compared to CMC mesh. In our previous paper [26], it was highlighted that major changes in ECM deposition and modulation occurred during the first 14 days and, for these reasons, we focused on day 7 after cell seeding for mass spectrometry analyses. Besides collagen type III, also myosin regulatory light chain $12 \mathrm{~B}$ and $78 \mathrm{kDa}$ glucoseregulated protein resulted to be overexpressed on PCL7-2i, while $60 \mathrm{kDa}$ heat shock protein was downregulated.

Myosin regulatory light chains are important for the maintenance of cell morphology and dynamic [50]. $78 \mathrm{kDa}$ glucose-regulated protein is a endoplasmatic reticulum (ER) chaperone involved in assembly and quality control of proteins [51]. It is expressed on the cell membrane and released in the cell culture medium [52], and its synthesis is induced by the accumulation of unfolded polypeptides 


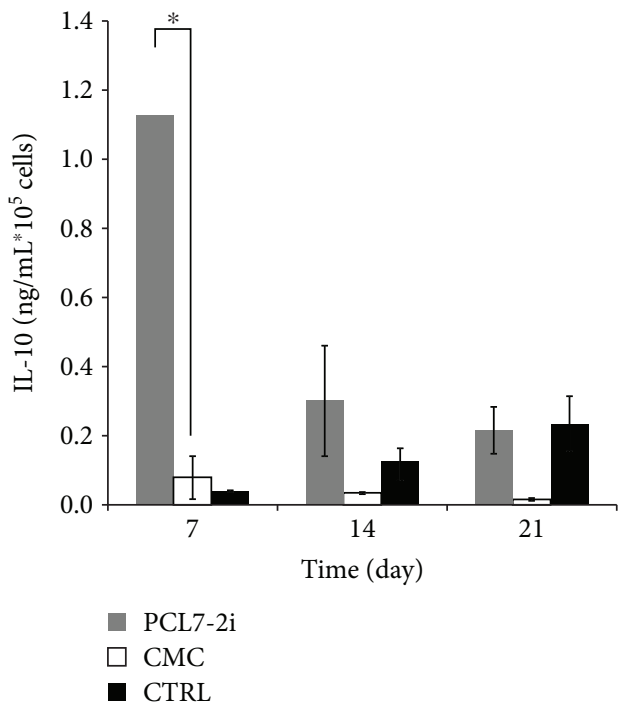

(a)

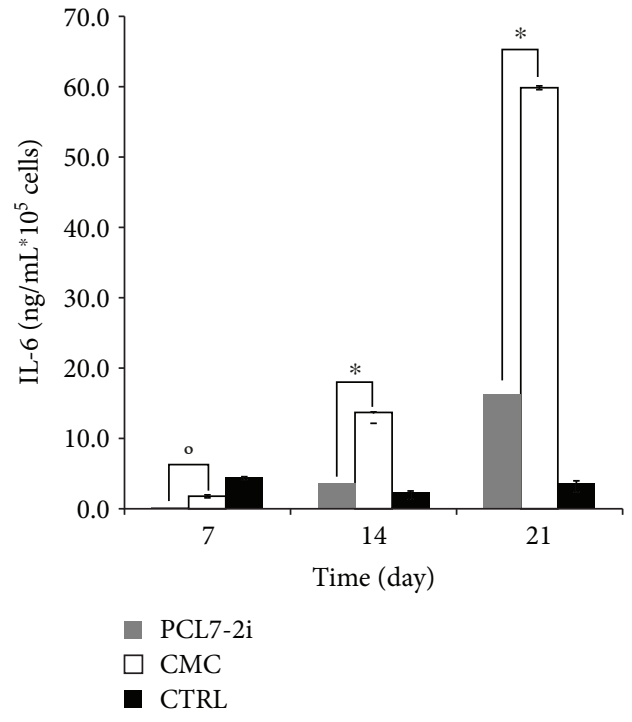

(b)

Figure 5: Interleukin-10 (a) and 6 (b) trend in PCL7-2i and control samples. ${ }^{*} p<0.0001$ and ${ }^{\circ} p=0.0002$.

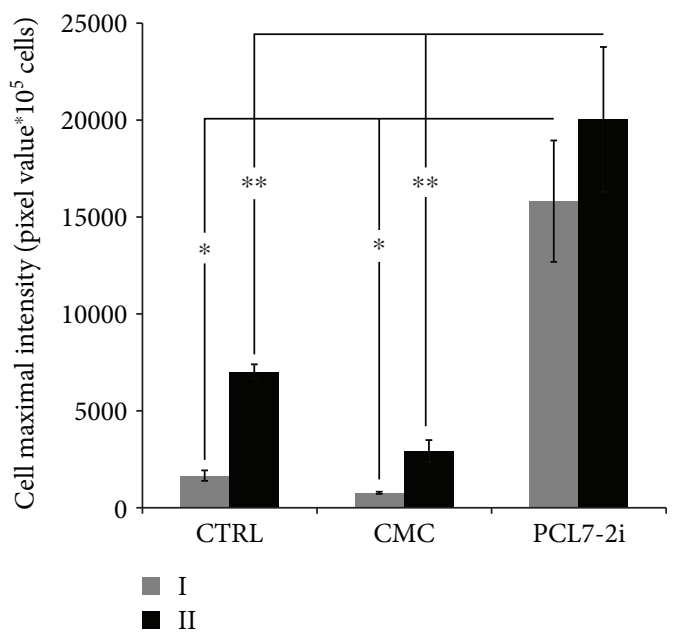

(a)

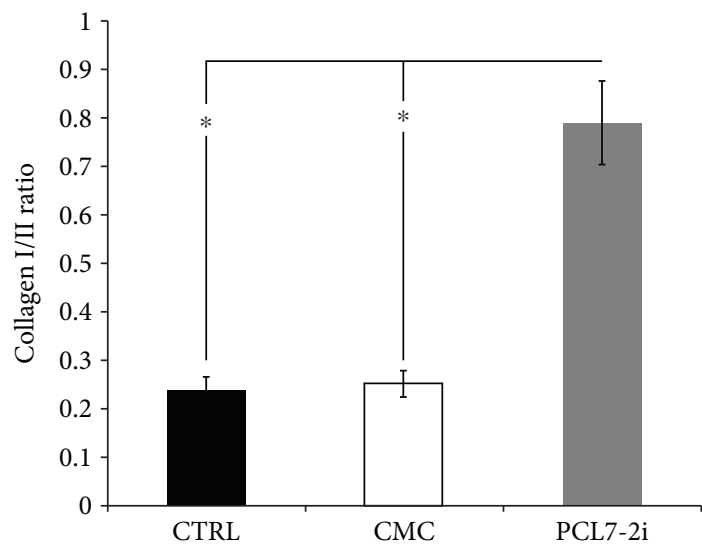

(b)

Figure 6: Collagen type I and type III production $\left((\mathrm{a}) ;^{*}\right.$ and $\left.{ }^{* *} p<0.0001\right)$ and in collagen type I/type III ratio ((b); $\left.{ }^{*} p<0.0001\right)$ in PCL7-2i and control samples.

TABLE 5: Differentially expressed proteins in ECM protein analysis.

\begin{tabular}{lccccc}
\hline Gene name & Protein name & $t$-test & $P$ value & Fold change & \\
\hline GRP78_HUMAN & 78 kDa glucose-regulated protein & -35.557 & 0.00079 & 0.468 & Upregulation in PCL7-2i \\
CO3A1_HUMAN & Collagen alpha-1 (III) chain & -12.545 & 0.00629 & 0.447 & Upregulation in PCL7-2i \\
ML12B_HUMAN & Myosin regulatory light chain 12B & -10.756 & 0.00853 & 0.417 & Upregulation in PCL7-2i \\
CH60_HUMAN & 60 kDa heat shock protein, mitochondrial & 4.495 & 0.04608 & 3.388 & Downregulation in PCL7-2i \\
\hline
\end{tabular}

in the ER. It is interesting that this protein is overexpressed in cancer and stressed cells, in which it can be actively secreted and assume roles in controlling cell signaling, proliferation, invasion, inflammation, and apoptosis [53]. Its induction and secretion on PCL7-2i could represent a useful answer to a stress state, leading to cell proliferation and invasiveness of the membrane. Also, the $60 \mathrm{kDa}$ heat shock protein is a chaperonin mainly involved in mitochondrial protein folding and translocation, but it is also suggested as a danger signal of stressed or damaged cells [54]. This protein resulted to be slightly underrepresented on PCL7-2i. 
This work represents the first step for the development of a new generation of resorbable hernia scaffolds. In particular, a porous PCL membrane (PCL7-2i) was selected among four different PCL porous membranes, based on its physicochemical and biomechanical properties, cytocompatibility, and cell growth properties, and then further characterized for its detailed biological behavior. Results showed that the PCL7$2 \mathrm{i}$ membrane could be potentially applied in abdominal wall hernia treatment. In fact, the analysis of biological response of PCL7-2i membranes showed that this type of scaffold is able to mechanically and structurally replicate the reference tissue and to support cell colonization. This was highlighted by the high cell growth rate on the scaffold, its minimal inflammatory response, potentially avoiding undesirable side effects, and its modulation of ECM synthesis with the support of stable forms of collagen and of proteins related to cell proliferation and colonization. All these aspects could contribute to scaffold integration.

Further tests will be aimed at the in vivo validation of PCL7-2i in order to evaluate its effectiveness in surgical treatment.

\section{Data Availability}

The data used to support the findings of this study are available from the corresponding author upon request.

\section{Conflicts of Interest}

The authors declare that they have no conflicts of interest.

\section{Acknowledgments}

This work was funded by MANUNET 2011 ERA-Net Project (MES-STAR-Morphologically Engineered Scaffold for Soft Tissue Application and Regeneration).

\section{Supplementary Materials}

Figure S1: a comparison between FTIR-ATR spectra of PCL, PEG2, and PCL/PEG2 60/40 films before and after PEG2 removal. The same results have been observed for samples containing $30 \%$ (wt) of PEG2 or PEG1 as porogen. Figure S2: the classification of proteins extracted from CMC and PCL7-2i membranes with respect to their cellular localization. Table S1: the 243 proteins extracted from CMC and PCL7-2i membranes and identified by mass spectrometry analysis. (Supplementary Materials)

\section{References}

[1] J. W. A. Burger, J. F. Lange, J. A. Halm, G.-J. Kleinrensink, and H. Jeekel, "Incisional hernia: early complication of abdominal surgery," World Journal of Surgery, vol. 29, no. 12, pp. 16081613, 2005.

[2] V. Singhal, P. Szeto, T. J. VanderMeer, and B. Cagir, "Ventral hernia repair: outcomes change with long-term follow-up," Journal of the Society of Laparoendoscopic Surgeons, vol. 16, no. 3, pp. 373-379, 2012.
[3] R. J. Fitzgibbons, A. T. Richards, and T. H. Quinn, "Open hernia repair," in ACS Surgery: Principles and Practice, W. S. Souba, P. Mitchell, M. P. Fink, G. J. Jurkovich, L. R. Kaiser, W. H. Pearce, J. H. Pemberton, and N. J. Soper, Eds., Decker Publishing Inc., Philadelphia, USA, 6th edition, 2002.

[4] F. Helgstrand, J. Rosenberg, H. Kehlet, L. N. Jorgensen, and T. Bisgaard, "Nationwide prospective study of outcomes after elective incisional hernia repair," Journal of the American College of Surgeons, vol. 216, no. 2, pp. 217228, 2013.

[5] J. Dalenbäck, C. Andersson, D. Ribokas, and G. Rimbäck, "Long-term follow-up after elective adult umbilical hernia repair: low recurrence rates also after non-mesh repairs," Surgery, vol. 17, no. 4, pp. 493-497, 2013.

[6] M. W. Christoffersen, F. Helgstrand, J. Rosenberg, H. Kehlet, P. Strandfelt, and T. Bisgaard, "Long-term recurrence and chronic pain after repair for small umbilical or epigastric hernias: a regional cohort study," American Journal of Surgery, vol. 209, no. 4, pp. 725-732, 2015.

[7] D. R. Flum, K. Horvath, and T. Koepsell, "Have outcomes of incisional hernia repair improved with time?," Annals of Surgery, vol. 237, no. 1, pp. 129-135, 2003.

[8] H. W. Harris, "Clinical outcomes of biologic mesh: where do we stand?," Surgical Clinics of North America, vol. 93, no. 5, pp. 1217-1225, 2013.

[9] A. Lukasiewicz, J. Skopinska-Wisniewska, A. Marszalek, S. Molski, and T. Drewa, "Collagen/polypropylene composite mesh biocompatibility in abdominal wall reconstruction," Plastic and Reconstructive Surgery, vol. 131, no. 5, pp. 731e740e, 2013.

[10] F. C. Usher, J. Ochsner, and L. L. Tuttle Jr., "Use of marlex mesh in the repair of incisional hernias," The American Surgeon, vol. 24, no. 12, pp. 969-974, 1958.

[11] B. P. Jacob, N. J. Hogle, E. Durak, T. Kim, and D. L. Fowler, "Tissue ingrowth and bowel adhesion formation in an animal comparative study: polypropylene versus Proceed versus Parietex Composite," Surgical Endoscopy, vol. 21, no. 4, pp. 629633, 2007.

[12] J. E. Losanoff, B. W. Richman, and J. W. Jones, "Entero-colocutaneous fistula: a late consequence of polypropylene mesh abdominal wall repair: case report and review of the literature," Surgery, vol. 6, no. 3, pp. 144-147, 2002.

[13] A. Jezupovs, A. Jezupors, and M. Mihelsons, "The analysis of infection after polypropylene mesh repair of abdominal wall hernia," World Journal of Surgery, vol. 30, no. 12, pp. 2270 2278, 2006.

[14] S. Kalaba, E. Gerhard, J. S. Winder, E. M. Pauli, R. S. Haluck, and J. Yang, "Design strategies and applications of biomaterials and devices for hernia repair," Bioactive Materials, vol. 1, no. 1, pp. 2-17, 2016.

[15] R. D. Rice, F. S. Ayubi, Z. J. Shaub, D. M. Parker, P. J. Armstrong, and J. W. Tsai, "Comparison of Surgisis, AlloDerm, and Vicryl Woven Mesh grafts for abdominal wall defect repair in an animal model," Aesthetic Plastic Surgery, vol. 34, no. 3, pp. 290-296, 2010.

[16] M. W. Laschke, J. M. Häufel, C. Scheuer, and M. D. Menger, "Angiogenic and inflammatory host response to surgical meshes of different mesh architecture and polymer composition," Journal of Biomedical Materials Research Part B: Applied Biomaterials, vol. 91, no. 2, pp. 497-507, 2009. 
[17] U. Klinge, "Functional assessment and tissue response of short- and long-term absorbable surgical meshes," Biomaterials, vol. 22, no. 11, pp. 1415-1424, 2001.

[18] K. Baylón, P. Rodríguez-Camarillo, A. Elías-Zúñiga, J. A. Díaz-Elizondo, R. Gilkerson, and K. Lozano, "Past, present and future of surgical meshes: a review," Membranes, vol. 7, no. 3, 2017.

[19] M. Chen, P. K. Patra, S. B. Warner, and S. Bhowmick, "Role of fiber diameter in adhesion and proliferation of NIH 3T3 fibroblast on electrospun polycaprolactone scaffolds," Tissue Engineering., vol. 13, no. 3, pp. 579-587, 2007.

[20] M. Plencner, B. East, Z. Tonar et al., "Abdominal closure reinforcement by using polypropylene mesh functionalized with poly- $\varepsilon$-caprolactone nanofibers and growth factors for prevention of incisional hernia formation," International Journal of Nanomedicine, vol. 9, pp. 3263-3277, 2014.

[21] M. R. Williamson, E. F. Adams, and A. G. A. Coombes, "Gravity spun polycaprolactone fibres for soft tissue engineering: interaction with fibroblasts and myoblasts in cell culture," Biomaterials, vol. 27, no. 7, pp. 1019-1026, 2006.

[22] R. Jakubova, A. Mickova, M. Buzgo et al., "Immobilization of thrombocytes on PCL nanofibres enhances chondrocyte proliferation in vitro," Cell Proliferation, vol. 44, no. 2, pp. 183-191, 2011.

[23] A. Thapa, T. J. Webster, and K. M. Haberstroh, "Polymers with nano-dimensional surface features enhance bladder smooth muscle cell adhesion," Journal of Biomedical Materials Research, vol. 67, no. 4, pp. 1374-1383, 2003.

[24] M. D. Bhavsar and M. M. Amiji, "Development of novel biodegradable polymeric nanoparticles-in-microsphere formulation for local plasmid DNA delivery in the gastrointestinal tract," AAPS PharmSciTech, vol. 9, no. 1, pp. 288-294, 2008.

[25] T. K. Dash and V. B. Konkimalla, "Poly- $\epsilon$-caprolactone based formulations for drug delivery and tissue engineering: a review," Journal of controlled release: official journal of the Controlled Release Society., vol. 158, no. 1, pp. 15-33, 2012.

[26] F. Vozzi, I. Guerrazzi, J. Campolo et al., "Biological and proteomic characterization of a composite mesh for abdominal wall hernia treatment: reference study," Journal of Biomedical Materials Research Part B: Applied Biomaterials, vol. 105, no. 7, pp. 2045-2052, 2017.

[27] A. N. Buxton, J. Zhu, R. Marchant, J. L. West, J. U. Yoo, and B. Johnstone, "Design and characterization of poly(ethylene glycol) photopolymerizable semi-interpenetrating networks for chondrogenesis of human mesenchymal stem cells," Tissue Engineering, vol. 13, no. 10, pp. 2549-2560, 2007.

[28] J. A. Beamish, J. Zhu, K. Kottke-Marchant, and R. E. Marchant, "The effects of monoacrylated poly(ethylene glycol) on the properties of poly(ethylene glycol) diacrylate hydrogels used for tissue engineering," Journal of Biomedical Materials Research Part A, vol. 92, no. 2, pp. 441-450, 2010.

[29] H. E. desJardins-Park, D. S. Foster, and M. T. Longaker, "Fibroblasts and wound healing: an update," Regenerative Medicine, vol. 13, no. 5, pp. 491-495, 2018.

[30] I. A. Darby, B. Laverdet, F. Bonté, and A. Desmoulière, "Fibroblasts and myofibroblasts in wound healing," Clinical, Cosmetic and Investigational Dermatology, vol. 7, pp. 301-311, 2014.

[31] "Polymer Properties Database," https://polymerdatabase.com/ polymer\%20classes/Intro.html.
[32] B. Wunderlich, Macromolecular Physics, Crystal Nucleation, Growth, Annealing, Academic, New York, NY, USA, 1976.

[33] C. De Maria, S. Burchielli, C. Salvadori et al., "The influence of mesh topology in the abdominal wall repair process," Journal of Biomedical Materials Research Part B: Applied Biomaterials, vol. 104, no. 6, pp. 1220-1228, 2016, 2nd ed.

[34] I. Felemovicius, M. E. Bonsack, G. Hagerman, and J. P. Delaney, "Prevention of adhesions to polypropylene mesh," Journal of the American College of Surgeons, vol. 198, no. 4, pp. 543-548, 2004.

[35] F. Agresta, A. Marzetti, S. Vigna, D. Prando, R. Porfidia, and S. Di Saverio, "Repair of primary and incisional hernias using composite mesh fixed with absorbable tackers: preliminary experience of a laparoscopic approach with a newly designed mesh in 29 cases," Updates in Surgery, vol. 69, no. 4, pp. 493-497, 2017.

[36] G. Munegato, L. Fei, M. Schiano di Visconte, D. Da Ros, L. Moras, and G. Bellio, "A new technique for tension-free reconstruction in large incisional hernia," Updates in Surgery, vol. 69, no. 4, pp. 485-491, 2017.

[37] W.-J. Lin and C.-H. Lu, "Characterization and permeation of microporous poly( $\varepsilon$-caprolactone) films," Journal of Membrane Science, vol. 198, no. 1, pp. 109-118, 2002.

[38] T. Ozeki, H. Yuasa, and Y. Kanaya, "Control of medicine release from solid dispersion composed of the poly(ethylene oxide)-carboxyvinylpolymer interpolymer complex by varying molecular weight of poly(ethylene oxide)," Journal of controlled release, vol. 58, no. 1, pp. 87-95, 1999.

[39] T. Velnar, T. Bailey, and V. Smrkolj, "The wound healing process: an overview of the cellular and molecular mechanisms," The Journal of International Medical Research, vol. 37, no. 5, pp. 1528-1542, 2009.

[40] R. Sabat, G. Grütz, K. Warszawska et al., "Biology of interleukin-10," Cytokine and Growth Factor Reviews, vol. 21, no. 5, pp. 331-344, 2010.

[41] J. Scheller, C. Garbers, and S. Rose-John, "Interleukin-6: from basic biology to selective blockade of pro-inflammatory activities," Seminars in Immunology, vol. 26, no. 1, pp. 2-12, 2014.

[42] R. A. Canuto, S. Saracino, M. Oraldi et al., "Colonization by human fibroblasts of polypropylene prosthesis in a composite form for hernia repair," Surgery, vol. 17, pp. 241-248, 2012.

[43] C. G. Pereira-Lucena, R. Artigiani-Neto, G. J. Lopes-Filho et al., "Experimental study comparing meshes made of polypropylene, polypropylene + polyglactin and polypropylene + titanium: inflammatory cytokines, histological changes and morphometric analysis of collagen," Hernia, vol. 14, no. 3, pp. 299-304, 2010.

[44] R. T. Hannan, S. M. Peirce, and T. H. Barker, "Fibroblasts: diverse cells critical to biomaterials integration," ACS Biomaterials Science \& Engineering, vol. 4, no. 4, pp. 1223-1232, 2018.

[45] J. M. Anderson, "Exploiting the inflammatory response on biomaterials research and development," Journal of Materials Science: Materials in Medicine, vol. 26, no. 3, p. 121, 2015.

[46] A. Fachinelli and M. R. Maciel Trindade, "Qualitative and quantitative evaluation of total and types I and III collagens in patients with ventral hernias," Langenbeck's Archives of Surgery, vol. 392, no. 4, pp. 459-464, 2007, 3rd ed.

[47] M. Vaz, R. K. Krebs, E. N. Trindade, and M. R. M. Trindade, "Fibroplasia after polypropylene mesh implantation for 
abdominal wall hernia repair in rats," Acta Cirúrgica Brasileira, vol. 24, no. 1, pp. 19-25, 2009.

[48] G. Pascual, B. Hernández-Gascón, M. Rodríguez et al., "The long-term behavior of lightweight and heavyweight meshes used to repair abdominal wall defects is determined by the host tissue repair process provoked by the mesh," Surgery, vol. 152, no. 5, pp. 886-895, 2012.

[49] E. Peeters, G. De Hertogh, K. Junge, U. Klinge, and M. Miserez, "Skin as marker for collagen type I/III ratio in abdominal wall fascia," Hernia, vol. 18, no. 4, pp. 519-525, 2014.

[50] I. Park, C. Han, S. Jin et al., "Myosin regulatory light chains are required to maintain the stability of myosin II and cellular integrity," The Biochemical Journal, vol. 434, no. 1, pp. 171180, 2011.

[51] J. Yang, M. Nune, Y. Zong, L. Zhou, and Q. Liu, "Close and allosteric opening of the polypeptide-binding site in a human Hsp70 chaperone BiP," Structure, vol. 23, no. 12, pp. 21912203, 2015.

[52] A. Delpino and M. Castelli, "The $78 \mathrm{kDa}$ glucose-regulated protein (GRP78/BIP) is expressed on the cell membrane, is released into cell culture medium and is also present in human peripheral circulation," Bioscience Reports, vol. 22, no. 3-4, pp. 407-420, 2002.

[53] A. S. Lee, "Glucose-regulated proteins in cancer: molecular mechanisms and therapeutic potential," Nature Reviews Cancer, vol. 14, no. 4, pp. 263-276, 2014.

[54] K. Ohashi, V. Burkart, and S. Flohé, "Cutting edge: heat shock protein 60 is a putative endogenous ligand of the toll-like receptor-4 complex," The Journal of Immunology, vol. 164, no. 2, pp. $558-561,2000$. 


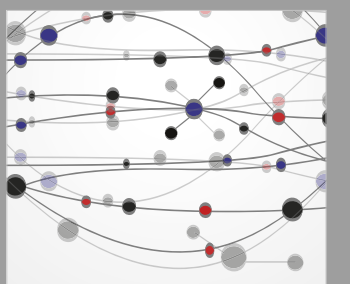

The Scientific World Journal
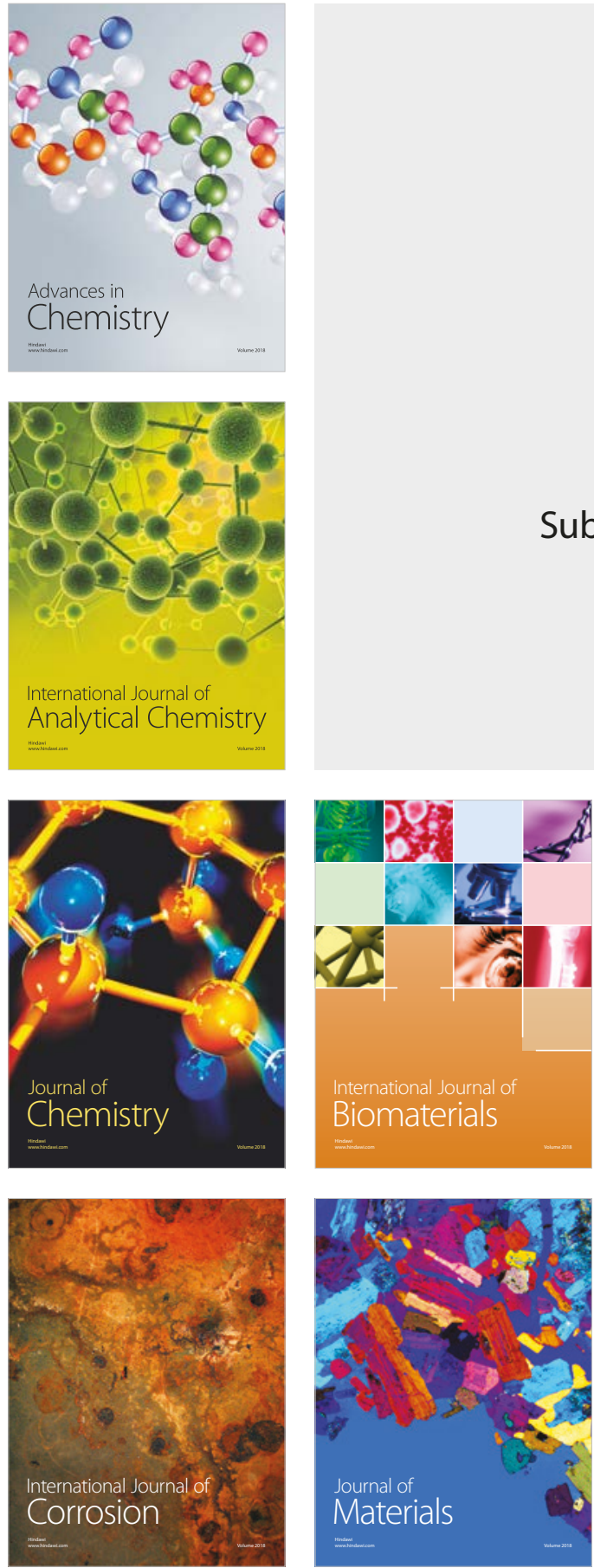

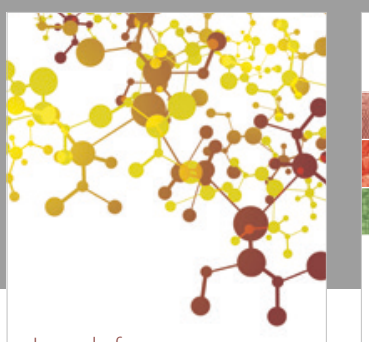

Journal of

Applied Chemistry
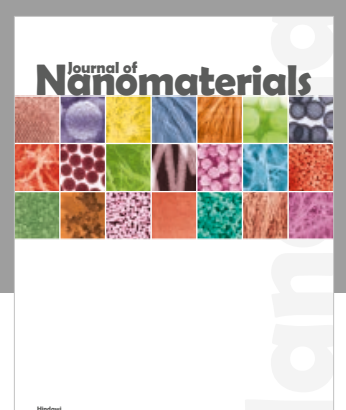

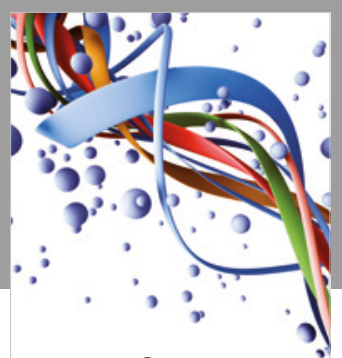

Scientifica

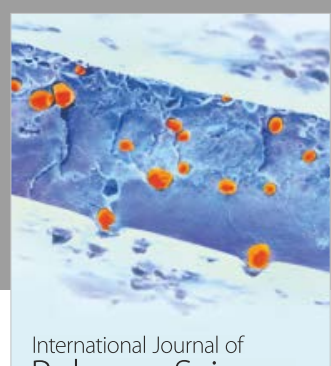

Polymer Science

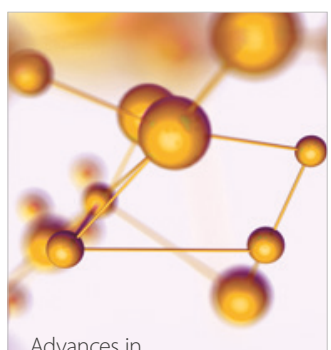

Physical Chemistry
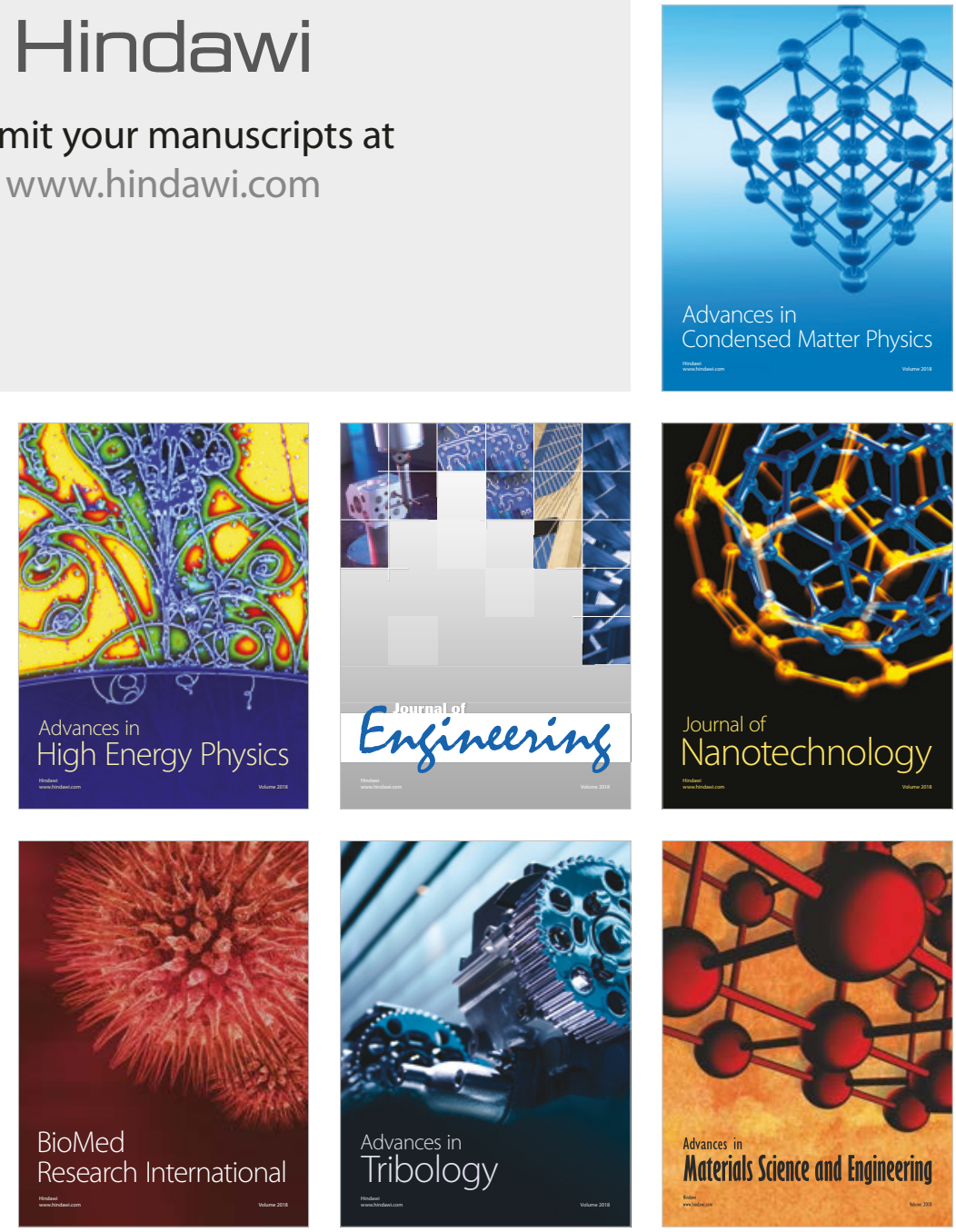